\title{
What cannot be measured cannot be done; risk factors for childhood tuberculosis: a case control study
}

\author{
Karim MR ${ }^{1}$, Rahman MA ${ }^{1}$, Mamun $\mathrm{SAA}^{1}$, Alam MA ${ }^{2}$, Akhter $\mathrm{S}^{3}$ \\ ${ }^{1}$ Department of Epidemiology, National Institute of Preventive and Social Medicine, Mohakhali, Dhaka, \\ ${ }^{2}$ Department of Maternal and Child health National Institute of Preventive and Social Medicine, Mohakhali, \\ Dhaka, ${ }^{3}$ AMC, Combined Military Hospital, Dhaka Cantonment, Dhaka, Email: shameem.m25@gmail.com
}

\begin{abstract}
Childhood tuberculosis is one of the major causes of childhood mortality and morbidity though much neglected within our National Tuberculosis Control Program. This case control study was carried out to identify the risk factors for tuberculosis among children. Cases $(n=95)$ and controls $(n=94)$ were selected from Directly Observed Treatment Short Course (DOTS) centers of four upazillas of Dhaka and Gazipur districts. Cases were childhood tuberculosis patient, who were test positive by sputum microscopy from January to May, 2011 and controls were children who visited DOTS laboratory suspecting tuberculosis infection but were sputum negative. Both cases and controls were selected from the sputum examination registers and were traced at home for exposure data. The study showed more girls were infected than boys. Several socio demographic and environmental factors were found to be associated with the development of childhood tuberculosis. Logistic regression model was constructed to find out the important predictors which revealed age, education of the respondents, indoor environment and contact pattern were significantly associated with childhood tuberculosis. Children more than 14 years of age had 6.25 times higher risk of developing childhood tuberculosis; (Odds ratio $=6.25 ; 95 \% \mathrm{CI}$ for $\mathrm{OR}=2.00$ to 19.55 ), Children completed primary education had 3.12 times lower risk of developing childhood tuberculosis, (Odds ratio $=.32 ; 95 \% \mathrm{CI}$ for $\mathrm{OR}=.10$ to 1.00 ). Those who resided in better in-house environment had 4.35 times lower risk of developing childhood tuberculosis (Odds ratio=.23; 95\% CI for $\mathrm{OR}=.06$ to .95) and children came in contact with source tuberculosis cases who were their relatives or neighbors were 5.26 times lower risk of developing childhood tuberculosis than being in contact with family members with TB (Odds ratio=.19; 95\% CI for $\mathrm{OR}=.07$ to .49). Contact Screening should be incorporated in National TB program for early detection and effective treatment of tuberculosis. Improvement of indoor environment and ventilation status of the bedroom might reduce the risk of developing childhood tuberculosis.
\end{abstract}

\section{Introduction}

Globally, of the 9.2 million new tuberculosis cases, about one million $(11 \%)$ are children ${ }^{1}$. It is now estimated that every year, 300,000 people in Bangladesh develop active tuberculosis, putting an immense burden on the economy and the health system, particularly for reproductive and child health $^{2}$. Childhood tuberculosis is under reported in Bangladesh due to difficulties in confirming diagnosis, lack of guidelines in the field of systematic screening and referral of children suspected to have tuberculosis ${ }^{3-4}$. Of the total number of newly detected sputum smear positive TB cases reported in 2008, children aged less than 14 years constituted only three percent. These are only smear positive cases which is a gross underestimate because young children cannot effectively produce sputum, and mostly their infection is pulmonary smear negative and extrapulmonary 5 .

Study showed age played a crucial role among the risks of being infected with tuberculosis. Children from birth to the age of 14 years have a lower risk of developing active TB compared to those at other ages. In 2001, the TB notification rates were 5.4, $3.5,13.5$, and 52.5 per 100000 for those aged " 0 to $4 "$, "5 to 9", "10 to 14 ", and "15 to 19 years", respectively ${ }^{6}$.

Some social and economic risk factors for childhood TB e.g. crowding, economic status, and education were significantly associated with the TB case notification rate in children 0-5 years old $^{7-8}$. Other factors like, the absence of a ceiling, walls made of mud, household crowding, and a history of 
TB in another member of the household were found to be associated with TB disease $\mathrm{e}^{9-10}$.

Childhood tuberculosis was found to be significantly associated with prolonged intimate contact with index cases in almost all studies. Recent study revealed, children aged 5 years who were contacts of source cases had significantly greater likelihood of being infected with increasing smear-positivity $(\mathrm{p}=0.01, \mathrm{OR}=2.25 ; 95 \% \mathrm{CI}=1.19$ to 4.27$)^{11-12}$. Studies in Gambia; West Africa, found that the risk of positive Tuberculin Skin Test (TST) response in the child increased with household TB infection proximity and with the degree of activities shared with the individual with tuberculosis ${ }^{13}$.

Infection in children progresses to disease more rapidly and more often than adult. Childhood tuberculosis indicates recent acquisition of mycobacterium tuberculosis, and children with latent infection provide a reservoir for future adult disease. In Bangladesh, Child tuberculosis is neglected as well as poor studied regarding factors responsible for its aggravation. This study may be helpful to take preventive measures against childhood tuberculosis, and thus may reduce this disease related morbidity and mortality.

\section{Materials and Methods}

This case control study was carried out to identify risk factors for tuberculosis among children. The exposure status of the newly diagnosed Childhood TB patients, who were sputum positive at the peripheral laboratory (cases) were collected and compared with the exposure information of the children who were sent to the laboratory suspecting tuberculosis infection but were sputum negative(controls). Cases were children under 18 years of age TB patients, diagnosed at four upazilla (Trishal, Bhaluka, Gofargaon, were from Mymensingh and Kapasia from Gazipur district) DOTS service centers from January to May, 2011. Children who visited DOTS laboratory but were sputum negative during the same time period (January to May) were taken as control. Their addresses were taken from the sputum microscopy register with a view to trace them at home for exploring exposure information.

Sample size was determined using Epi-info software. Assuming anticipated probability of "exposure" given "no disease" 32\%, anticipated odds ratio 2.44 , $5 \%$ level of significance, $80 \%$ power, the estimated sample size were 91 cases and 91 controls. In this study, 95 cases and 94 controls were enrolled.
Literacy was determined whether anyone ever had any institutional education or not. Occupational status of the parents was collected in all possible categories and afterwards recoded into two broad categories. Person per bedroom was calculated and categorized taking two persons per room as cut-off point.

Household condition was constructed by composing floor material, wall material and roof material of the residence of the study samples and classified primarily into very poor, poor, average, and good category respectively. Then these conditions were further categorized into poor and good category. "Kitchen position" and "number of windows in bedroom" variables were combined to compose indoor environment category. Houses that had no windows, kitchen attached to the house or had indoor cooking arrangement were named as poor in-house environment. Houses that had one or more windows, kitchen attached to the house or had cooking arrangement inside the room were named as moderate in-house environment. Houses that had separate kitchen were termed as good in-house environment. Contact information was collected as four different states.

1 Patients reported not knowing each other and no possible point of contact could be identified

2 Patients who reported not knowing each other but for whom casual contact was possible (e.g. sharing a transport route regularly or living in the same sub-district).

3 Patients who reported knowing each other by name, but acquaintance was only casual;

4 Patients who knew each other well and had prolonged or intimate contact (e.g. family members, friends).

Based on the relationship and proximity of source cases, contact status was further subdivided into two categories (e.g. contact with family members, contact with relatives and neighbours). Duration of contact was taken in months of being contact with tuberculosis patient. Samples who were confused and who responded "do not know" were deliberately excluded while analyzing contact exposure.

Each of the respondents was informed about the objective of the study, assured and verbal consent was taken. Data were collected by face to face interview with the aid of a researcher administered structured questionnaire and reviewing records.

To ensure quality control, continuous supervisory support was given by the research investigators. All the questionnaires were checked for 
consistency and completeness and a subset of questionnaires was re-checked in the field for validity.

Collected data were entered using SPSS program and thereafter cleaned \& edited. Statistical tests $\left(\chi^{2}\right)$ were performed to determine the association between exposure and outcome variables. Logistic regression model was constructed to find out the influence of each exposure variables after correcting the effect for other variables. Adjusted Odds ratios with $95 \%$ confidence interval were calculated and reported.

\section{Results}

This case control study was carried out among 95 childhood tuberculosis patients and 94 controls. The mean age of cases and controls were almost same and it was around 14 years. Figure 1 shows the age distribution of the respondents. Female children were in higher proportion among cases $\mathrm{n}=54(56 \%)$ than male $\mathrm{n}=43 \quad(44 \%)$. Among control, male respondent contributed $n=51 \quad(55 \%)$ and female $n=41(45 \%)$ (Table-I).

Figure 2 shows that the proportion of female children $n=29(31 \%)$ is about two times higher than of male children $n=17(18 \%)$ in "more than 14 years" category. The proportion of TB infection is higher within older age category $(n=46,57 \%)$, though not significantly statistically associated $(\mathrm{p}=.16)($ Table-I).

Educational status of the children and developments of childhood tuberculosis were statistically significantly associated. Children completed primary education are 2.63 times less likely to develop tuberculosis than preprimary children ( $\mathrm{p} .006$, crude Odds ratio $=.38 ; 95 \% \mathrm{CI}=.19$ to .74) (Table-I). It is important to mention that 7 children, who were illiterate, all had tuberculosis in this study sample.

Maternal education $(\mathrm{p}=.001)$ and occupational status $(\mathrm{p}=.04)$, both were statistically significantly associated with childhood tuberculosis. There was no significant association between fathers' educational status $(\mathrm{p}=.11)$ as well as occupational status $(\mathrm{p}=.12)$ and childhood tuberculosis infection (Table-I).

Child tuberculosis was found to be statistically significantly associated with the stability of the family composition $(\mathrm{p}=.001)$. Almost all the respondents were the permanent resident $n=181$ $(96 \%)$ of different village area and used to live in their own houses $\mathrm{n}=182$ (96\%). Bedroom occupancy (person per bedroom) was statistically significantly associated with the development of childhood tuberculosis $(\mathrm{p}=<0.0001)$ (Table-I)

Household conditions were statistically significantly associated with the developments of childhood tuberculosis $(\mathrm{p}=<0.0001)$ (Table-II). Sixteen cases lived in very poor household condition whereas none of the controls had such household status. After recoding household conditions into poor and good category, there found no association $(\mathrm{p}=.51)$ (Table-III).

Only three percent of the household $n=6$ had no windows, 144 houses $(76 \%)$ had only one window and the rest 39 household had two or more exterior windows (Table-II).

More than $98 \%$ of the study population $n=186$, took tube well water for drinking and cooking. All of them, both cases and controls had sanitary latrine except four. Seventeen percent $(n=32)$ of the household used kerosene lamp for lighting and the rest of the households, $n=156(82.5 \%)$ had electricity. Kitchen position was found to be associated with childhood tuberculosis. $(\mathrm{p}=.001$, crude $\mathrm{OR}=.35 ; 95 \% \mathrm{CI}$ for $\mathrm{OR}=.20$ to .62). This might be due to, separate kitchen reflected a better economic status and the houses that had separate kitchen might enjoy better in-house environment (Table-III).

In-house environment was statistically significantly associated with development of childhood tuberculosis. Children lived in moderate in-house environment were three times less likely to develop tuberculosis; $(\mathrm{p}=<0.0001$, crude $\mathrm{OR}=.29 ; 95 \%$ CI for $\mathrm{OR}=.11$ to78); and children lived in good inhouse environment were four times less likely to develop tuberculosis than those lived in poor inhouse environment (crude $\mathrm{OR}=.25$; 95\% CI for $\mathrm{OR}=.13$ to .49) (Table-III). Children came in contact with relatives having tuberculosis were five times less likely to develop tuberculosis than those came in contact with the family members with tuberculosis $(\mathrm{p}=<0.0001$, Crude odds ratio $=.20$; $95 \%$ CI for $\mathrm{OR}=.10$ to .38). Relationship of the duration of contact and development of childhood tuberculosis was statistically significantly associated $(\mathrm{p}=<0.005$, Crude odds ratio=3.6; 95\% CI for $\mathrm{OR}=1.52$ to 8.54 ) (Table-III).

During preliminary analysis, several socio demographic and environmental factors were found to be associated with the development of childhood tuberculosis. A binary logistic regression model was constructed to find out the predictors of childhood tuberculosis adjusting for other factors. The predictors in the model revealed that children more than 14 years of age had 6.25 times higher 
risk of developing childhood tuberculosis (Odds ratio $=6.25 ; 95 \% \mathrm{CI}$ for $\mathrm{OR}=2.00$ to 19.55 ) and those who completed primary education had 3.12 times lower risk of developing childhood tuberculosis (Odds ratio $=.32 ; 95 \%$ CI for $\mathrm{OR}=.10$ to 1.00). Children resided in better ventilated houses had 4.35 times lower risk of developing childhood tuberculosis (Odds ratio $=.23 ; 95 \% \mathrm{CI}$ for $\mathrm{OR}=.06$ to .95$)$. Children came in contact with relatives or neighbors having tuberculosis were 5.26 times lower risk of developing childhood tuberculosis than those came in contact with family members with tuberculosis, when adjusted for other factors (Odds ratio=.19; 95\% CI for $\mathrm{OR}=.07$ to .49) (Table-IV).

There were nine children who had no BCG scar. Among them eight children had tuberculosis sparing only one. More than $95 \%$ of the cases were found with cough and fever and one third of the cases had haemoptysis at the time of diagnosis.

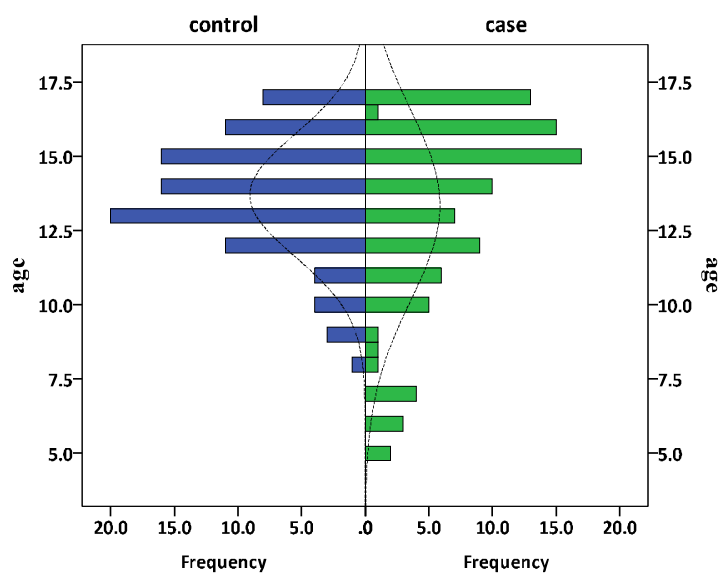

Figure 1. Distribution of respondents by age

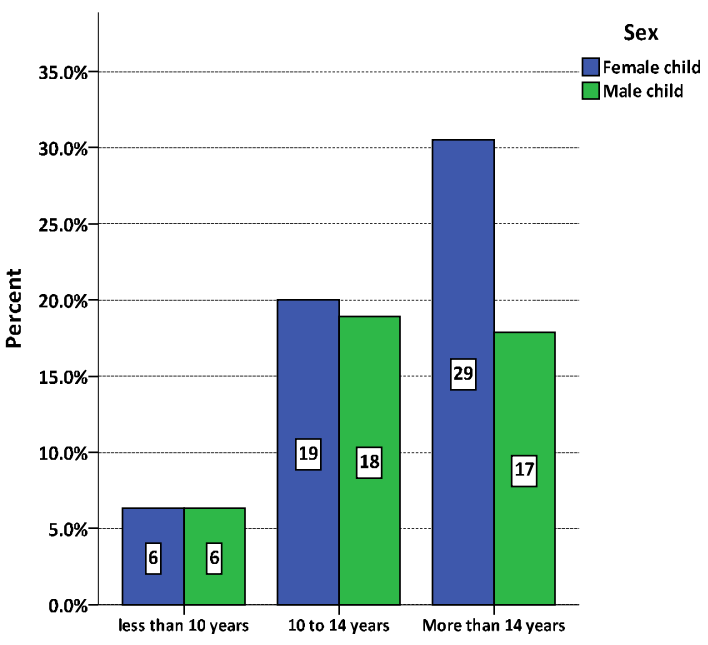

Figure 2. Distribution of age category of childhood tuberculosis by sex
Table I: Distribution of socio-demographic variables among the respondents

\begin{tabular}{|c|c|c|c|c|}
\hline \multirow[t]{2}{*}{ Characteristics } & Control & Case & \multirow{2}{*}{$\begin{array}{c}\mathrm{p} \\
\text {-value }\end{array}$} & \multirow{2}{*}{$\begin{array}{l}\text { Crude odds } \\
\text { ratio with } \\
(95 \% \mathrm{Cl})\end{array}$} \\
\hline & $\mathrm{n}(\%)$ & $\mathrm{n}(\%)$ & & \\
\hline \multicolumn{5}{|l|}{ Age of the respondents } \\
\hline$\dagger$ Less than 14 years & $59(55)$ & $49(45)$ & & \\
\hline More than 14 years & $35(43)$ & $46(57)$ & .16 & $1.58(.89,2.83)$ \\
\hline \multicolumn{5}{|l|}{ Sex } \\
\hline$\dagger$ Female & $43(44)$ & $54(56)$ & & \\
\hline Male & $51(55)$ & $41(45)$ & .17 & $.64(.36,1.14)$ \\
\hline \multicolumn{5}{|l|}{ Education level } \\
\hline$\dagger$ Preprimary & $17(33)$ & $35(67)$ & & \\
\hline Primary and above & $77(56)$ & $60(44)$ & .006 & $.38(.19, .74)$ \\
\hline \multicolumn{5}{|l|}{ Mothers' education } \\
\hline$\dagger$ Illiterate & $47(64)$ & $26(36)$ & & \\
\hline Literate & $47(41)$ & $69(59)$ & .002 & $2.65(1.45,4.86)$ \\
\hline \multicolumn{5}{|l|}{ Mothers' occupation } \\
\hline$\dagger$ Housewife & $88(52)$ & $80(48)$ & & \\
\hline Others & $6(29)$ & $15(71)$ & .07 & $2.75(1.02,7.43)$ \\
\hline \multicolumn{5}{|l|}{ Fathers' education } \\
\hline$\dagger$ Pre-primary & $38(58)$ & $27(42)$ & & \\
\hline Primary and above & $56(45)$ & $68(55)$ & .11 & $1.71(.93,3.14)$ \\
\hline \multicolumn{5}{|l|}{ Fathers' occupation } \\
\hline †Wage labour & $55(45)$ & $67(55)$ & & \\
\hline Business and service & $39(58)$ & $28(42)$ & .12 & $.59(.32,1.08)$ \\
\hline \multicolumn{5}{|l|}{ Family composition } \\
\hline$†$ Stable & $29(74)$ & $10(26)$ & & \\
\hline Unstable & $65(43)$ & $85(57)$ & .001 & $3.79(1.73,8.34)$ \\
\hline \multicolumn{5}{|l|}{ Persons per bed room } \\
\hline$\dagger$ Less than two person & $52(67)$ & $26(33)$ & & \\
\hline More than two person & $42(38)$ & $69(62)$ & .000 & $.29(1.79,6.03)$ \\
\hline
\end{tabular}

Table-II: Distribution of the household condition among cases and controls

\begin{tabular}{lcccc}
\hline characteristics & $\begin{array}{c}\text { Control } \\
\mathrm{n}(\%)\end{array}$ & $\begin{array}{c}\text { Case } \\
\mathrm{n}(\%)\end{array}$ & \multicolumn{1}{c}{$\chi^{2}$} & $\mathrm{p}$ value \\
\hline $\begin{array}{l}\text { Household condition of } \\
\text { the respondent }\end{array}$ & & & & \\
$\begin{array}{l}\text { Very poor household } \\
\text { condition }\end{array}$ & $0(0)$ & $16(100)$ & & \\
$\begin{array}{l}\text { Poor household } \\
\text { condition }\end{array}$ & $42(57)$ & $32(43) * 20.31_{\mathrm{df}:}<0.0001$ \\
$\begin{array}{l}\text { Average household } \\
\text { condition }\end{array}$ & $39(51)$ & $38(49)$ & & \\
$\begin{array}{l}\text { Good household } \\
\text { condition }\end{array}$ & $10(53)$ & $9(47)$ & & \\
$\begin{array}{l}\text { Presence of window } \\
\text { (ventilation status!) }\end{array}$ & & & & \\
No windows & & & & \\
One window & $2(33)$ & $4(67)$ & & \\
Two or more window & $19(49)$ & $20(51)$ & \\
\hline
\end{tabular}


Table III: Distribution of the household and contact variables among cases and controls

\begin{tabular}{|c|c|c|c|c|}
\hline Characteristics & $\frac{\text { Control }}{\mathrm{n}(\%)}$ & $\begin{array}{l}\text { Case } \\
\mathrm{n}(\%)\end{array}$ & $\begin{array}{c}\mathrm{p} \\
\text { value }\end{array}$ & $\begin{array}{l}\text { Crude odds } \\
\text { ratio with } \\
(95 \% \mathrm{Cl})\end{array}$ \\
\hline \multicolumn{5}{|l|}{ Household condition } \\
\hline †Poor & $42(47)$ & $48(53)$ & & \\
\hline Good & $52(53)$ & $47(47)$ & .51 & $.79(.45,1.4)$ \\
\hline \multicolumn{5}{|l|}{ Kitchen position category } \\
\hline $\begin{array}{l}\text { †Kitchen attached to bedroom or } \\
\text { in-house cooking }\end{array}$ & $34(37)$ & $59(63)$ & .001 & $.35(.2, .62)$ \\
\hline Separate kitchen & $60(63)$ & $36(37)$ & & \\
\hline \multicolumn{5}{|l|}{ In-house environment category } \\
\hline †Poor (In house kitchen \& no vent) & $21(30)$ & $50(70)$ & & \\
\hline Moderate(In house kitchen+ vent) & $13(59)$ & $9(41)$ & & $.29(.11, .78)$ \\
\hline Good (Separate kitchen) & $60(63)$ & $36(37)$ & .000 & $.25(.13, .49)$ \\
\hline \multicolumn{5}{|l|}{ Contact relation } \\
\hline †Family contact & $18(26)$ & $52(74)$ & & \\
\hline Relatives and neighbors & $76(64)$ & $43(36)$ & .000 & $.20(.10, .38)$ \\
\hline \multicolumn{5}{|l|}{ Duration of contact } \\
\hline tLess than 2 years & $22(69)$ & $10(31)$ & & \\
\hline More than 2 years & $33(38)$ & $54(62)$ & .005 & $3.6(1.52,8.54)$ \\
\hline
\end{tabular}

$\dagger=$ reference category, $* *=$ statistically significant, $\mathrm{OR}=$ odds ratio, $\mathrm{CI}=$ confidence interval

Table IV: Predictors of childhood tuberculosis in binary logistic regression model

\begin{tabular}{|c|c|c|c|c|}
\hline \multirow[t]{2}{*}{ Predictors } & \multirow[t]{2}{*}{$\begin{array}{c}\mathrm{P} \\
\text { value }\end{array}$} & \multirow[t]{2}{*}{$\begin{array}{l}\text { Odds } \\
\text { ratio } \\
\text { (OR) }\end{array}$} & \multicolumn{2}{|c|}{$\begin{array}{l}95 \% \text { confidence } \\
\text { interval for odds } \\
\text { ratio }\end{array}$} \\
\hline & & & Lower & Upper \\
\hline More than 14 years of age & .002 & 6.25 & 2.00 & 19.55 \\
\hline Female versus male & .33 & .63 & .25 & 1.61 \\
\hline Primary and above education & .05 & .32 & .10 & 1.00 \\
\hline Literate mothers & .14 & 1.62 & .86 & 3.05 \\
\hline Working mothers & .22 & 2.65 & .56 & 12.50 \\
\hline Unstable family composition & .09 & 4.20 & .80 & 22.05 \\
\hline More than 2 person/room & .12 & 2.32 & .81 & 6.64 \\
\hline Good housing condition & .66 & 1.25 & .47 & 3.34 \\
\hline In house kitchen with vent & .04 & .23 & .06 & .95 \\
\hline Separate kitchen & .84 & .90 & .31 & 2.56 \\
\hline More than 2 years contact & .48 & 1.54 & .46 & 5.12 \\
\hline contact witn otner tnan raminy & .001 & .19 & .07 & .49 \\
\hline
\end{tabular}

\section{Discussion}

According to our national picture, the male-female ratio is $2: 1$ among the TB patients aged below 14 years. In this study, the frequency of male and female child TB cases are almost equal below 14 years of age and on the contrary frequency of female child TB cases were two times higher than those in male child ( $>14$ years) category, consistent with other reports ${ }^{1,5}$. This age distribution may lead us with the assumption that female children usually stay closer \& longer with the family than their male counterpart. It is important that, girls at the brink of their reproductive age are developing the deadly disease, who are either difficult to trace after marriage or their family may conceal the TB infection status for marital purpose. Besides, this infection status increase the chance of spreading tuberculosis in a new setting (husband's family) and also imposes long term risk on her nutritional and reproductive status. The present study showed higher proportion of older children (>14 years) among the cases which correspond with previous studies ${ }^{11}$.

Educational level of the children was low among cases than the controls which contradict with national data where $51 \%$ children completed the primary level of education ${ }^{14}$. Child tuberculosis was found to be associated with educational attainment and also working status of mother in bivariate analyses but found not significant in multivariate analysis. Children of working mothers' had more chance to develop tuberculosis which contradicts previous studies ${ }^{10}$. Literate parents involved them in various jobs resulting less attention to their children.

The present study showed that, children of the wage laborer had the higher proportion of infection which corresponds to a study where children of service holders had significant reduced risk $(p=0.039)$ to develop TB than others ${ }^{10}$. Increased size of household was found to be important in previous studies and overcrowding has been documented as a risk factor for TB from several other studies in a variety of settings ${ }^{9-10,15}$. In this study, bedroom occupancy (person per bedroom) and in-house environment were found statistically significantly associated with the developments of childhood tuberculosis. Measurement of the bedroom area might not reflect the area of the actual bed room size because of the fact that in every bedroom there were number of furniture, utensils, stored crops, agricultural tools, bundles of firewood, jute-straw and blankets etc. There were some places for pet animals, (hens, ducks, goats etc) too. Number of windows reflected vague expression of ventilation because the position and size of the windows were not uniform.

In this study, researcher found the household contact which was the important risk factor for TB is consistent with other previous studies where $24 \%$ of West African TB cases had a family history of TB compared to $10 \%$ of controls $(\mathrm{P}<0.001$, OR= $3.24 ; 95 \%$ CI 2.3 to 4.6$)^{15}$. In another study $45 \%$ of cases reported household exposure to a known TB case, compared to $11 \%$ of controls. This finding is 
of substantial public health importance ${ }^{16}$. Presence of BCG vaccination scar was observed higher among controls than cases. It was suggested that when given to children at their early ages gave about $75 \%$ protection for 15 years ${ }^{17}$.

Childhood TB usually have nonspecific clinical signs, variable chest X-ray features; infection is paucibacillary in nature with low bacteriological confirmation rates. Diagnosis of tuberculosis in children relied mainly on clinical case-definition; tuberculin skin testing and chest radiography ${ }^{18}$. In this study, only smear positive cases were taken which might not explore the true exposure status of childhood tuberculosis. As it was a case control study, there might have potential chance for recall bias. The controls were reluctant to provide information regarding frequency and duration of the exposure as well as contact history. As the Controls were taken from the DOTS microscopy center registers, they were seemingly more health conscious or might have easy access to the centre. So the controls might not be representative in terms of rural setting.

Conclusion: Tuberculosis prevention program in Bangladesh mostly focuses on detecting and treating index cases rather identifying the risk factors for TB transmission. Identifying cases earlier in their illness will require a combination of approaches. Latent tuberculosis infection should be screened and contact investigation should be incorporated as part of National TB program. Improvement of indoor environment and ventilation status of the bedroom could minimize the risk of developing childhood tuberculosis.

\section{Acknowledgement}

We humbly acknowledge the financial support of National Tuberculosis Control Program for funding us to conduct this research.

\section{References}

1. WHO REPORT 2008 | Global Tuberculosis Control. http://www.who.int/tb/publications/global_report/en/.

2. Global tuberculosis control report, WHO: 2009. http://data.unaids.org/pub/Report/2008/who 2008 global tb report en.pdf.

3. Tuberculosis- Fact sheets -TB and Children. searo.who.int/en/Section10/Section2097/Section2106_ 10681.htm, 27 April 2006.

4. National Tuberculosis Control Program, National Guidelines and Operational Manual for Tuberculosis Control. 4th Edition. DGHS, MOH\&FW. Dhaka: 2009.

5. Zaman K, Yunus M, Arifeen SE, Baqui AH, Sack DA. Prevalence of sputum smear-positive tuberculosis in a rural area in Bangladesh. Epidemiology and Infection 2006;134: 1052-1059.

6. Leung CC, Yew WW, Chang KC, Tam CM, Chan CK, Law WS, et al. Risk of Active tuberculosis among School-children in Hong Kong Arch Pediatr Adolesc Med. 2006;160:247-251.

7. Riea A, Beyersa N, Giea RP, Kunnekeb M, Zietsmanb L, Donalda PR. Childhood tuberculosis in an urban population in South Africa: burden and risk factor. Arch Dis Child 1999; 80:433-437 doi:10.1136/ adc. 80.5.433.

8. Tipayamongkholgul M, Podhipak A, Chearskul S and Sunakorn P. Factors associated with the development of tuberculosis in bcg immunized children. January 2005;Vol 36: No.1

9. Hill PC, Sillah DJ, Donkor SA, Otu1 J, Adegbola RA and Lienhardt C. Risk factors for pulmonary tuberculosis: a clinic-based case control study in The Gambia. BMC Public Health 2006, 6:156 doi:10.1186/1471-2458-6-156.

10. Singh M, Mynak ML, Kumar L, Mathew JL, Jindal SK. Prevalence and risk factors for transmission of infection among children in household contact with adults having pulmonary tuberculosis. Arch Dis Child 2005; 90:624-628.

11. Vashishtha VM and John TJ from Mangla Hospital, Shakti Chowk, Bijnor, Uttar Pradesh, India. Prevalence of Mycobacterium tuberculosis Infection in Children in Western Uttar Pradesh. January17, 2010; volume 47.

12. Sinfield R, Nyirenda M, Haves S, Molyneux EM \& Graham SM. University of Liverpool, UK. Risk factors for TB infection and disease in young childhood contacts in Malawi. Annals of Tropical Paediatrics 2006; 26:205-213.

13. Manneh K, Warndorff $\mathrm{D}$, Bennett $\mathrm{S}$, Adam KM, Lienhardt C, Sillah J et al. Risk Factors for Tuberculosis Infection in Children in Contact with Infectious Tuberculosis Cases in The Gambia, West Africa. Pediatrics 2003; 111: e608-e614.DOI: 10.1542/peds.111.5.e608.

14. Directorate of Primary Education, Annual Sector Performance Report. 2008.

15. Lienhardt C, Fielding K, Sillah JS, Bah B, Gustafson $\mathrm{P}$, Warndorff $\mathrm{D}$ et al.Investigation of the risk factors for tuberculosis: a case-control study in three countries in West Africa. Int J Epidemiol 2005, 34:914-923.

16. Donald PR. Childhood tuberculosis in an urban population in South Africa: burden and risk factor. Arch Dis Child 1999; 80: 433-437.

17. Soysal A, Millington KA, Bakir M, Dosanjh D, Aslan Y, Deeks JJ, et al. Effect of BCG vaccination on risk of Mycobacterium tuberculosis infection in children with household tuberculosis contact: a prospective community-based study. Lancet. 2005;366:1443-1451.

18. Ahmed T, Sobhan F, Ahmed S, Banu S, Mahmood AM, Hyder KA et al. Childhood Tuberculosis: a Review of Epidemiology, Diagnosis and Management. Infect Dis J. Apr - Jun 2008;17(2):52-60. 